\title{
Nivel de la tasa de filtrado glomerular para iniciar el protocolo de trasplante, evaluación de urolitiasis, proteinuria y hematuria en el receptor de trasplante renal
}

\author{
Glomerular filtration rate level to start the transplant protocol, \\ evaluation of urolithiasis, proteinuria and hematuria \\ in the kidney transplant recipient
}

Sergio Hernández-Estrada*

* Departamento de Nefrología y Unidad de Trasplante Renal. Centro Médico Nacional 20 de Noviembre ISSSTE.

\section{NIVEL DE LA TASA DE FILTRADO GLOMERULAR PARA INICIAR UN PROTOCOLO DE TRASPLANTE.}

\section{Resumen}

- Vigilar que el trasplante renal (TR) sea viable en el receptor.

- Atender que la supervivencia del paciente no se afecte por el procedimiento de TR.

- Asegurarse de que el TR no exacerbará comorbilidades preexistentes.

El mejor momento para enlistar a un potencial candidato a trasplante renal (TR) es cuando en la consulta se descartan dos condiciones:

1. Que no exista un tiempo demasiado prolongado, cuya función renal es estable, y que se mantenga al receptor sin requerimiento de terapia de reemplazo renal (TRR) durante mucho tiempo. Por ejemplo, cuando se tiene un paciente hombre de 65 años con una tasa de filtrado glomerular (TFG) de $20 \mathrm{~mL} / \mathrm{min}$ con deterioro muy lento; este paciente ha permane- cido estable por mucho tiempo y, potencialmente, la cirugía de trasplante puede comprometer su condición clínica deteriorando la calidad de vida.

2. No iniciar demasiado tarde cuando se tengan complicaciones de un inicio retrasado de tratamiento sustitutivo renal (TSR) y complicaciones derivadas del inicio de la misma en distintas modalidades. Por ejemplo, una paciente mujer de 50 años que se encuentra en el Servicio de Urgencias con síndrome urémico y síndrome coronario agudo, cuando en consulta de nefrología se había planteado inicio de diálisis desde hace tres meses. Esta complicación retardaría el protocolo y eventualmente su cirugía de TR. ${ }^{1,2}$

Cabe señalar que existen razones para no enlistar o continuar un protocolo de TR en un receptor, aunque cada vez son menos las contraindicaciones absolutas. Sin embargo, estas razones siempre están encaminadas a conseguir un TR y no a suspenderlo. En este aspecto, por ejemplo, la edad avanzada, por sí sola, no debe ser una contraindicación. ${ }^{3,4}$ Por lo tanto, todos los pacientes deben ser estudiados para evaluar la viabilidad y descartar contraindicaciones para el TR. 
Cada uno de estos aspectos se tocarán de manera específica en cada una de las secciones.

De acuerdo con ciertas tendencias a nivel mundial, ${ }^{4,5}$ si el paciente tiene un donante vivo, se debe iniciar el protocolo para trasplantar antes de la entrada a TSR y antes de la realización del acceso vascular o de la colocación del catéter peritoneal, coincidiendo en varios centros con una TFG entre 15 y $20 \mathrm{~mL} / \mathrm{min}$ (TR anticipado). Esta determinación de la TFG por fórmula (CKD-EPI), basada en creatinina sérica, debe realizarse de acuerdo con la disponibilidad en la unidad hospitalaria. Si no se cuenta con el donante, idealmente se debe incluir al paciente a una lista de donante fallecido durante el proceso de decisión sobre el tipo de modalidad dialítica en un intento de TR prediálisis. Incluso como norma, se establece culminar el protocolo de TR seis meses antes de su entrada prevista a diálisis. ${ }^{4} \mathrm{En}$ otros países se sugiere la valoración del paciente para protocolo de TR desde el estadio 4 de la enfermedad renal crónica (ERC), es decir, con una TFG $<30 \mathrm{~mL} /$ min, con datos de deterioro rápido en la función renal. En este sentido, la representación gráfica de la relación entre la creatinina plasmática y el aclaramiento de creatinina reportada en otras publicaciones son útiles para predecir el comportamiento de la función renal. En nuestro país, ${ }^{2}$ se recomienda que en cuanto el paciente se encuentre en TRR y sus condiciones generales lo permitan, se debe comenzar un protocolo y enlistarlo para que se trasplante a la brevedad. El TR representa el tratamiento de elección de la ERC debido a la mejor calidad de vida en relación con los procedimientos de diálisis y también por presentar una mayor supervivencia. ${ }^{5}$

EI TR está indicado en pacientes con ERC en diálisis (hemodiálisis o diálisis peritoneal) o con ERC irreversible con un TFG generalmente por debajo de 15 $\mathrm{mL} / \mathrm{min}$. Finalmente, para iniciarse el protocolo de TR, se debe tomar en cuenta la velocidad de deterioro de la función renal dependiendo el perfil del paciente, tanto el que presenta deterioro lento con función limítrofe en TFG y que no justifica una urgencia culminar en $\mathrm{TR}$, como aquel joven que tiene un deterioro rápido, progresivo y predecible que justifica su estudio a corto plazo para poder trasplantarse oportunamente.

En la mayoría de las series, el TR anticipado confiere mejores resultados en comparación con pacientes que se trasplantaron una vez iniciada la TRR. ${ }^{6} \mathrm{De}$ manera reciente, se han reportado resultados en la supervivencia global y del injerto comparables entre los pacientes que se trasplantan de manera anticipada y aquéllos con diálisis pretrasplante menor a 19 meses. $^{7}$
Sin embargo, de manera global, se prefiere trasplantar anticipadamente a la llegada a diálisis o con periodos cortos una vez iniciada en la mayoría de los países, ya que existe evidencia de menor pérdida de injerto, muerte con injerto funcionante o enfermedad cardiovascular posterior al trasplante. ${ }^{8}$

\section{UROLITIASIS EN EL RECEPTOR}

\section{Resumen}

- La urolitiasis es una causa metabólica común que ocasiona problemas urológicos, uropatía obstructiva y enfermedad renal crónica (ERC).

- No existen datos o registros en nuestro país de la incidencia de novo de urolitiasis después del trasplante renal.

- En pacientes con urolitiasis como causa principal de ERC, se sugiere solicitar un perfil metabólico urinario si es posible.

- La hiperoxaluria primaria es corregida únicamente con el trasplante hepático o se puede realizar un trasplante combinado hígado/riñón.

- Nefrocalcinosis al inicio de protocolo de TR obliga a estudiar la causa de fondo, y brindar tratamiento si la causa es reversible.

- La nefrectomía de riñones nativos previa al TR tiene indicaciones específicas.

De manera habitual, cuando se realiza una detección de la ERC avanzada y si no existe contraindicación, se inicia el protocolo de TR. En muchos pacientes, no se tiene el diagnóstico etiológico, sin embargo, en aquéllos con urolitiasis, se tiene conocimiento de esta enfermedad y ésta se constituye como suficiente para deteriorar la función renal a largo plazo.

La litiasis renal es una causa metabólica común, que ocasiona problemas urológicos y condiciona uropatía obstructiva y ERC. ${ }^{9}$ Se menciona una prevalencia de 7 a $8 \%$ en población adulta a nivel mundial, con una recurrencia de hasta el $30 \%$ a 10 años. La incidencia va en aumento en países industrializados, con una prevalencia global estimada reciente de 10 a $15 \%$. Además, diversas cifras concuerdan en que $13 \%$ de los hombres y $7 \%$ de las mujeres tendrán un episodio de litiasis renal al menos una vez en su vida. En nuestro país, ${ }^{9}$ la incidencia de litiasis depende de la región geográfica, en donde la exposición a más altas temperaturas (como en el sureste) condicionan una elevación en su incidencia. Al final, es una enfermedad multifactorial en la que pueden estar implicados 
factores intrínsecos, como los genéticos, la raza, la edad y el sexo; y factores extrínsecos, como los geográficos, los climáticos, alimentarios y los relacionados con la actividad laboral. Dependiendo de la raza, se reporta predilección por distintos tipos de litiasis, por ejemplo, en el Mediterráneo, el $75 \%$ de las litiasis son por cristales de ácido úrico, mientras que en Occidente e incluyendo nuestro país, la etiología que predomina son los litos dependientes de sales cálcicas hasta en un $70 \%{ }^{1,9}$

Algunos estudios reportan que la recurrencia de la litiasis renal es menor cuando la TFG es menor, es por esto que pacientes con ERC en estadios de prediálisis tienen menos episodios de litiasis $(<1 \%)$. Estos pacientes, una vez trasplantados, cuentan con una mejoría significativa en la TFG, con mejoría de igual forma en la excreción urinaria de metabolitos que en algún momento condicionaron litiasis renal aguda. ${ }^{1}$ Posteriormente, en la evolución del TR, los pacientes pueden presentar cuadros de litiasis en el injerto renal y esto nos habla de la importancia del estudio del receptor renal previo a TR. Aquí se tiene la intención de documentar la causa metabólica en la medida de lo posible, así como corregir los trastornos metabólicos para disminuir la incidencia de nuevos episodios de litiasis renal. Esto cobra relevancia, porque hoy en día no existen datos o registros en nuestro país de la incidencia de novo de litiasis renal después del TR. ${ }^{1,9}$

Derivado de lo anterior, en pacientes con litiasis renal como causa principal de ERC, se sugiere solicitar un perfil metabólico urinario para determinar su etiología, ${ }^{10}$ ya que los cálculos están distribuidos de la siguiente manera: el $60-70 \%$ de todos los cálculos están constituidos por oxalato cálcico, sólo o con alguna forma de fosfato; los cálculos de fosfato-amónicomagnésico o los relacionados con una infección aparecen en el 5-10\% de los casos; los de ácido úrico en el $10-15 \%$, y los de cistina en el $1 \% .{ }^{11}$

Con la prueba metabólica, se realizan principalmente los siguientes diagnósticos:3,11

1. Hipercalciuria: se define por un aumento mantenido en la eliminación urinaria de calcio en ausencia de hipercalcemia y de otras causas conocidas de hipercalciuria. Es la causa más frecuente de litiasis renal tanto en la edad pediátrica como en la adulta. Ésta amerita ser específica en la etiología de la hipercalciuria para establecer el tratamiento óptimo.

2. Hiperuricosuria: deben considerarse los niveles plasmáticos de ácido úrico para separar la sobre- producción de ácido úrico, en general asociado con hiperuricemia y la hiperuricosuria per se. Se define como una excreción superior a $800 \mathrm{mg} / \mathrm{día}$ en el hombre y $750 \mathrm{mg} / \mathrm{dí}^{\mathrm{a}}$ en las mujeres. ${ }^{12}$

3. Hiperoxaluria: se define como una eliminación urinaria de oxalato superior a $45-50 \mathrm{mg} / \mathrm{día}$. Como etiologías, se tiene la ingesta excesiva de oxalato, síndromes de mala absorción (oxaluria entérica) o deficiencia hereditaria enzimática que conlleva a exceso en el metabolismo de oxalato (hiperoxaluria primaria). Esta última entidad es corregida únicamente con el trasplante hepático o se puede considerar el realizar trasplante combinado hígado/riñón para disminuir la oxalosis. ${ }^{13}$

4. Hipocitraturia: se considera con valor inferior a 300 $\mathrm{mg} / \mathrm{día}$ para ambos sexos y/o un valor del cociente entre las concentraciones de citrato y creatinina inferior a $250 \mathrm{mg} / \mathrm{g}$. Las principales causas son la acidosis tubular renal, ERC y asociada con hipercalciuria idiopática. Otras causas son el tratamiento con acetazolamida o tiazidas, la depleción de potasio, la inanición y la malabsorción intestinal.

5. Cistinuria: se consideran valores de eliminación urinaria de cistina, una excreción inferior a $200 \mathrm{mg} /$ día o un cociente menor de $18 \mathrm{mg} / \mathrm{g}$ de creatinina. La enfermedad se hereda de modo autosómicorecesivo. Se caracteriza por la recurrencia de cálculos de cistina; más de un $50 \%$ de los pacientes cistinúricos desarrollará litiasis durante su vida, y un $75 \%$ en ambos riñones. Ésta es la enfermedad litiásica más compleja de tratar con un alto índice de recidiva.

6. Estruvita o litiasis asociada a infecciones: también llamadas de triple fosfato, requieren la presencia de bacterias formadoras de ureasa como Ureaplasma, Proteus, Klebsiella, Serratia, etc. Pueden presentarse cálculos complicados o coraliformes que ameritan tratamiento intervencionista o quirúrgico.

De igual forma, la nefrocalcinosis es una condición que se refiere al aumento del depósito de calcio en el riñón y puede estar relacionada con trastornos del calcio, alteraciones tubulares, enfermedad anatómica (riñón medular o en esponja), asociación con fármacos (acetazolamida, anfotericina) y de tipo cortical (tuberculosis, trauma, glomerulonefritis o incluso en un injerto con rechazo crónico). Si se documenta este hallazgo en el inicio de protocolo de TR (estudios de imagen y perfil metabólico), estamos obligados a estudiar la causa de 
fondo y brindar tratamiento si la causa puede ser reversible. ${ }^{11}$

Respecto a los estudios de imagen, la valoración de urolitiasis del receptor previo al trasplante amerita principalmente lo siguiente: ${ }^{3}$

1. Ultrasonido: no invasivo, pues permite de manera rápida e inocua tomar mediciones, descartar dilatación de vía urinaria y evidenciar masa renal, quistes o litiasis sola o asociada con nefrocalcinosis. No evalúa la función renal.

2. Tomografía computada con protocolo de litiasis (sin contraste): complementa al ultrasonido, permite tanto evaluar los riñones nativos si existe sospecha de hallazgos añadidos (hidronefrosis, tumores, quistes) al tratamiento sustitutivo renal como evidencia del tamaño y localización de los litos renales.

En el candidato a TR, previo al procedimiento, otra situación a valorar en conjunto con el equipo quirúrgico es la nefrectomía de riñones nativos con litiasis. Las principales indicaciones de nefrectomía son:

1. Litiasis y poliquistosis con riñones gigantes que imposibilitan la colocación del injerto.

2. Nefrocalcinosis y/o sospecha de tumor renal.

3. Sepsis renal persistente asociada a nefrolitiasis. En general, la recomendación de nefrectomía de riñones nativos previo a TR considera un escenario de litiasis bilateral y complicada. ${ }^{3,14}$

Para concluir, se sugiere tomar en cuenta dentro del protocolo de estudio del candidato a TR lo siguiente:

1. Diagnóstico de la etiología de la urolitiasis (si es posible).

2. Determinar la morfología de los riñones por estudios de imagen.

3. Descartar causas corregibles de litiasis y administrar tratamiento si es factible.

4. Establecer si el receptor renal es candidato a nefrectomía de riñones nativos previo a TR en conjunto con urología o equipo de cirugía de trasplante, individualizando cada caso y siempre que exista una alteración renal bilateral y complicada. Posteriormente y con seguridad, se podrá proceder al TR con seguimiento en el periodo postquirúrgico y de acuerdo con los protocolos hospitalarios de cada institución.

\section{EVALUACIÓN DE PROTEINURIA Y HEMATURIA EN EL RECEPTOR}

\section{Resumen}

- La proteinuria es el principal marcador independiente de progresión de ERC en riñones nativos.

- La proteinuria previa a TR ayuda a establecer el seguimiento y pronóstico del injerto renal una vez trasplantado.

- Si existe una proteinuria nefrótica antes del TR que ponga en peligro la vida, se puede considerar nefrectomía, ya sea química, embolización o quirúrgica.

- La hematuria es una condición para evaluar en la consulta previo al TR, ya que puede manifestar globalmente actividad o nefritis en los riñones nativos o estar relacionada con una lesión en el tracto urinario.

- Si la hematuria es de origen glomerular, se debe valorar biopsia renal para determinar si es viable la etiología.

- Las complicaciones urológicas con hematuria implican la segunda causa de eventos adversos inmediatamente después del trasplante y hasta los primeros tres meses.

La proteinuria es el principal marcador independiente de progresión de ERC en riñones nativos. En el TR, puede significar la presencia de una lesión renal a nivel glomerular y tubulointersticial. También, se ha relacionado con una peor supervivencia del injerto y del paciente. La reducción de la proteinuria en los riñones nativos favorecerá una reducción de la progresión de la ERC, lo que condicionará un efecto favorable en el candidato a TR. ${ }^{15}$

La presencia de proteinuria debe ser determinada previa a TR en el receptor, ya que, al ser procedente de los riñones nativos, ayuda a tener una cifra basal de proteinuria residual de cara al seguimiento después del TR. Esta condición se puede presentar frecuentemente en los pacientes que reciben un TR anticipado o al poco tiempo de haber iniciado la terapia de sustitución renal. ${ }^{15,16}$

En ocasiones, la proteinuria previa al TR, aun y cuando es de rango nefrótico, disminuye abruptamente durante las primeras semanas después del TR cuando el injerto se encuentra normofuncionante. Esto se explica por la disminución del flujo sanguíneo de los riñones nativos y en donde dicho flujo es secuestrado de alguna manera por el injerto renal. Este principio se 
refuerza cuando en el seguimiento, se evidencia inicialmente una función del injerto disminuida, donde el flujo sanguíneo en los riñones nativos se mantiene y la proteinuria residual o nativa persiste. ${ }^{16}$

Por otro lado y en relación con la proteinuria residual, existen varios patrones de proteinuria después del TR; por ejemplo, los pacientes con injerto funcionante y que persisten con proteinuria mayor a $3 \mathrm{~g} /$ día a las tres semanas posterior al TR. Otros autores ${ }^{10}$ mencionan una proteinuria mayor a $1.5 \mathrm{~g} /$ día a un año de TR o un incremento de $500 \mathrm{mg} / \mathrm{día}$ desde la tercer semana posterior al TR como indicadores de disfunción del injerto. De manera global, la proteinuria de más de $1 \mathrm{~g} /$ día por más de tres meses después del TR que persiste obliga a descartar enfermedad glomerular o recurrencia de la enfermedad renal.

Derivado de la implicación que tiene la proteinuria posterior al TR, ${ }^{10,17,18}$ es importante la determinación del grado de proteinuria antes del TR para poder establecer seguimiento y pronóstico del injerto renal una vez trasplantado. Se debe realizar determinación de proteinuria en orina de 24 horas o albuminuria en orina de 24 horas para saber el grado de proteinuria, tipo de proteinuria y, en ese sentido, administrar el tratamiento médico correspondiente previo al TR.

Parte de las medidas generales antiproteinuria, de acuerdo con las guías internacionales, ${ }^{19}$ son: disminuir la TA sistólica con un tratamiento farmacológico de IECA O ARA2, restricción del sodio de la dieta a $5 \mathrm{~g} /$ día, restricción de la ingesta proteica a $0.8 \mathrm{~g} / \mathrm{kg}$ de peso/día, uso de tratamiento diurético eficaz, y un antagonista de la aldosterona al IECA o ARA2 en caso de proteinuria persistente, mantener tratamiento con estatinas, pérdida de peso y abandono del hábito tabáquico. Cuando existen datos de actividad de alguna nefropatía que condiciona proteinuria nefrótica y el paciente debe iniciar tratamiento específico, habrá que administrarlo oportunamente.

Si existe una proteinuria nefrótica previo al $\mathrm{TR}^{16,19}$ que condicione deterioro hemodinámico con hipoalbuminemia severa, edema refractario, trombosis, infecciones y desnutrición que alteren la cicatrización, así como refractariedad a tratamiento médico o que ponga en peligro la vida, se puede considerar nefrectomía química o embolización como tratamiento definitivo, sin embargo, la recomendación es individualizar cada caso.

Es por esto que todos los pacientes en protocolo de TR con uresis residual deben contar con determinación de proteinuria previa a trasplante para caracterizar la misma, ya que servirá de factor pronóstico después del TR..$^{10,16-19}$
La hematuria es una condición a evaluar previo al TR, ya que puede manifestar globalmente nefritis a nivel de riñones nativos o relacionarse con una lesión en el tracto urinario. ${ }^{19}$ En este sentido, la hematuria se divide en glomerular o no glomerular en función de la aparición de eritrocitos dismórficos o isomórficos en la mayoría de eritrocitos en el sedimento urinario. Cuando la hematuria está presente en candidatos a TR, estamos obligados a documentar su origen, ${ }^{19,20}$ para ello utilizaremos de manera secuencial el examen general de orina, sedimento urinario, urocultivo, estudios de imagen (ultrasonografía y tomografía abdominal multicorte) y estudios diagnósticos/invasivos (cistoscopia, cistouretrograma y estudio urodinámico) si se requiere para esclarecer la causa de la misma. Debido a la prevalencia de tuberculosis en nuestro país, se debe descartar activamente esta enfermedad antes del TR también.

Si la hematuria es de origen glomerular, ${ }^{21}$ generalmente se asocia con enfermedad inflamatoria en el riñón (glomerulonefritis) y antes de considerar avanzar en el protocolo de TR, se debe valorar, en la medida de lo posible, la realización de biopsia renal para determinar la causa y verificar si se amerita tratamiento previo a TR. También debe considerarse un periodo libre de enfermedad activa para la realización del TR de acuerdo con la etiología (en caso de documentarse). Esto cobra importancia por el riesgo de recidiva de enfermedad renal posterior al TR, condicionando una disminución en la supervivencia del injerto renal. Esto se revisará a detalle en el apartado de causas de ERC, riesgo de recidiva y enfermedades sistémicas.

Otra condicionante de la hematuria es la del tracto urinario o de origen urológico. 19,22 Las complicaciones urológicas con hematuria implican la segunda causa de un evento adverso en los primeros tres meses posterior al TR y se reportan en un 2.5 a $14 \%$, dependiendo de las distintas series, en las cuales se asocia a una elevación en la morbimortalidad, pérdida del injerto y mortalidad.

De manera integral y relacionado con la hematuria, se busca que el candidato a TR tenga un trasplante exitoso y se recomienda verificar las siguientes condiciones: ${ }^{22}$

1. Ausencia de infecciones complicadas en el tracto urinario.

2. Ausencia de litiasis.

3. Exclusión de malignidad en el tracto urinario.

4. Funcionalidad adecuada en el tracto urinario y a nivel vesical. 
Debemos identificar y tratar las causas de la hematuria antes del trasplante. Cuando esto no es posible, se deberá decidir si prosigue, se retrasa o se cancela el TR dependiendo de cada caso.

Por último, es importante señalar que tanto la proteinuria y la hematuria pueden estar presentes y combinarse, lo que hace sospechar la presencia de un síndrome glomerular, o también relacionarse con patología del tracto urinario, por lo que necesitará que el médico responsable proponga los estudios correspondientes arriba mencionados y el tratamiento específico previo a TR.

\section{REFERENCIAS}

1. Saran R, Li Y, Robinson B, Abbott KC, Agodoa LY, Ayanian $\mathrm{J}$ et al. United States Renal Data System 2015 annual data report: epidemiology of kidney disease in the United States. Am J Kidney Dis. 2016; 67: S1-S305.

2. Tratamiento Sustitutivo de la Función Renal. Diálisis y Hemodiálisis en la Insuficiencia Renal Crónica en el Segundo y Tercer Nivel de Atención. Guías de Práctica Clínica, CENETEC. México: Secretaría de Salud; 25 de septiembre 2014.

3. Abramowicz D, Cochat P, Claas FH, Heemann U, Pascual J, Dudley $\mathrm{C}$ et al. European Renal Best Practice Guideline on Kidney Donor and Recipient Evaluation and Perioperative Care. Nephrol Dial Transplant. 2015; 30 (11): 1790-1797.

4. Pérez-Tamajon L, Rufino-Hernández JM, Hernández-Marrero D. Evaluación del receptor de trasplante renal. En: Lorenzo V, López-Gómez JM. Nefrología al día. Disponible en: https:// www.nefrologiaaldia.org/es-articulo-evaluacion-del-receptortrasplante-renal-62.

5. Kidney Disease: Improving Global Outcomes (KDIGO) Transplant Work Group. KDIGO clinical practice guideline for the care of kidney transplant recipients. Am J Transplant. 2009; 9 Suppl 3: S1-155.

6. Arze Aimaretti L, Arze S. Preemptive renal transplantationthe best treatment option for terminal chronic renal failure. Transplant Proc. 2016; 48 (2): 609-611.

7. Kim HY, Choi JY, Kwon HW, Jung JH, Han M, Park SK et al. Comparison of clinical outcomes between preemptive transplant and transplant after a short period of dialysis in living-donor kidney transplantation: a propensity-score-based analysis. Ann Transplant. 2019; 24: 75-83.

8. Goto N, Okada M, Yamamoto T, Tsujita M, Hiramitsu T, Narumi $S$ et al. Association of dialysis duration with outcomes after transplantation in a Japanese cohort. Clin J Am Soc Nephrol. 2016; 11: 497-504.
9. Medina-Escobedo M, Zaidi M, Real-de León E, OrozcoRivadeneyra S. Urolithiasis prevalence and risk factors in Yucatan, Mexico. Salud Publica Mex. 2002; 44: 541-545.

10. Rodríguez Faba O, Boissier R, Budde K, Figueiredo A, Taylor CF, Hevia V et al. European Association of Urology Guidelines on Renal Transplantation: Update 2018. Eur Urol Focus. 2018; 4 (2): 208-215.

11. García-Nieto V, Luis-Yanez MI, Fraga-Bilbao F. Litiasis renal. En: Lorenzo V, López-Gómez JM. Nefrología al día. Disponible en: http://dev.nefro.elsevier.es/es-monografias-nefrologia-diaarticulo-litiasis-renal-5.

12. Treviño-Becerra A, Iseki K. Uric acid in chronic kidney disease. Contrib Nephrol. Basel, Karger. 2018; 192: 116-124.

13. Lorenzo-Sellares V, Torres A, Salido E. Hiperoxaluria primaria. Nefrología. 2014; 34 (3): 398-412.

14. letto G, Raveglia V, Zani E, lovino D, Parise C, Soldini G. Pretransplant nephrectomy for large polycystic kidneys in ADPKD patients: is peritoneal dialysis recovery possible after surgery? Biomed Res Int. 2019; 2019: 7343182.

15. Amer H, Cosio FG. Significance and management of proteinuria in kidney transplant recipients. J Am Soc Nephrol. 2009; 20 (12): 2490-2492.

16. Suárez ML, Cosio FG. Causas y consecuencias de la proteinuria después del trasplante renal. Nefrología. 2011; 31 (4): 404-414.

17. Diena D, Messina M, De Biase C, Fop F, Scardino E, Rossetti $\mathrm{MM}$ et al. Relationship between early proteinuria and long term outcome of kidney transplanted patients from different decades of donor age. BMC Nephrol. 2019; 20 (1): 443.

18. Lam NN, Tonelli M, Lentine KL, Hemmelgarn B, Ye F, Wen K et al. Albuminuria and posttransplant chronic kidney disease stage predict transplant outcomes. Kidney Int. 2017; 92 (2): 470-478.

19. Tai E, Chapman JR. The KDIGO review of the care of renal transplant recipient. Pol Arch Med Wewn. 2010; 120 (6): 237242.

20. Kasiske B, Cangro CB, Hariharan S. The evaluation of renal transplant candidates: clinical practice. Am J Transplant. 2001; 1 Suppl 2: 3-95.

21. Wang Z, Vathsala A, Tiong HY. Haematuria in postrenal transplant patients. Biomed Res Int. 2015; 2015: 292034.

22. Di Carlo HN, Darras FS. Urologic considerations and complications in kidney transplant recipients. Adv Chronic Kidney Dis. 2015; 22 (4): 306-311.

Correspondencia:

Dr. Sergio Hernández-Estrada

E-mail: sergiohernandezmed@ hotmail.com 